\title{
Gamification of the learning process: lessons learned
}

\author{
Faraón Llorens-Largo, Francisco J. Gallego-Durán, Carlos J. Villagrá-Arnedo, Patricia Compañ- \\ Rosique, Rosana Satorre-Cuerda, Rafael Molina-Carmona
}

\section{Title - Gamification of the learning process: lessons learned}

\begin{abstract}
Although several definitions of gamification can be found in the literature, they all have in common certain aspects: the application of strategies, models, dynamics, mechanics and elements of the games in other contexts than games, and the objective of producing a playful experience that fosters motivation, involvement and fun. In this paper, our approach gamifying the learning process of a subject is presented. Our experience throughout time in using games and gamification in learning have led us to propose, lately, a personalized, automated and gamified learning system. As a result of this experience and after several years of continuous feedback from our students, we have learned several lessons on how to approach the task of gamification. These lessons are summarized in the following concepts: fun, motivation, autonomy, progressiveness, feedback, error tolerance, experimentation, creativity and adaptation to the specific case. The final aim is sharing our experience and opening a debate about what key elements the gamification lies in.
\end{abstract}

Index Terms - gamification, fun, motivation, feedback, trial and error, experimentation, autonomy

\section{INTRODUCTION}

Gamification is a fashionable term. But what is gamification? As it happens in all new and expanding fields, there is no single unanimous definition, although most definitions incorporate a set of aspects that are widely accepted. The definition of gamification is complex and diverse, and it also depends on the environment it comes from, academic or industrial, since the main focus is on very different aspects. In order to determine the essence of the term, a brief review of some of the existing definitions is

Faraón Llorens-Largo, Departamento de Ciencia de la Computación e Inteligencia Artificial de la Universidad de Alicante, Apartado de correos 99, E-03080 Alicante, Spain (e-mail: Faraon.Llorens@ua.es).

Francisco J. Gallego-Durán, Departamento de Ciencia de la Computación e Inteligencia Artificial de la Universidad de Alicante, Spain (e-mail: fgallego@dccia.ua.es).

Carlos J. Villagrá-Arnedo, Departamento de Ciencia de la Computación e Inteligencia Artificial de la Universidad de Alicante, Spain (e-mail: villagra@dccia.ua.es).

Patricia Compañ-Rosique, Departamento de Ciencia de la Computación e Inteligencia Artificial de la Universidad de Alicante, Spain (e-mail: patricia@dccia.ua.es)

Rosana Satorre-Cuerda, Departamento de Ciencia de la Computación e Inteligencia Artificial de la Universidad de Alicante, Spain (e-mail: rosana@dccia.ua.es).

Rafael Molina-Carmona Departamento de Ciencia de la Computación e Inteligencia Artificial de la Universidad de Alicante, Spain (e-mail: rmolina@dccia.ua.es).

DOI (Digital Object Identifier) Pendiente done. According to Ramirez [1] "gamifying is implementing game strategies (thoughts and mechanics) in non-game contexts so that people adopt certain behaviours". For Marín and Hierro [2] "gamification is a technique, a method and a strategy at a time. It starts from the knowledge of the elements that make games attractive and identify, within an activity, task or particular message, in a non-game environment, those aspects that can be converted into games or into playful dynamics. The objective is achieving a special relationship with users, encouraging a change in their behaviour or transmitting a message or content. That is to say, creating a meaningful and motivating experience ". And if the definition of the website Gamificacion [3] is considered, "it is the use of game mechanics in non-game environments and applications in order to enhance motivation, concentration, effort, loyalty and other common positive values to all games". According to Gartner [4] "it is the use of game mechanics to drive engagement in nongame business scenarios and to change behaviours in a target audience to achieve business outcomes. Many types of games include game mechanics such as points, challenges, leader boards, rules and incentives that make game-play enjoyable. Gamification applies these to motivate the audience to higher and more meaningful levels of engagement. Humans are 'hard-wired' to enjoy games and have a natural tendency to interact more deeply in activities that are framed in a game construct". Deterding et al. [5] propose a simple definition of gamification: "the use of game design elements in non-game contexts", although they give more details in their article. Finally, Kapp [6] defines it as "using game-based mechanics, aesthetics and game thinking to engage people, motivate action, promote learning, and solve problems".

From all these definitions, it is possible to extract some common elements to make up a new definition. Gamification is the use of strategies, models, dynamics, mechanics and game elements in non-game contexts, in order to convey a message or a content or change behaviour through a playful experience that fosters motivation, involvement and fun. The most interesting approach from the educational point of view is that based on the concept of game thinking [7]. We therefore prefer to speak of gamifying as designing a process of any kind as you would do if you were designing a game. Participants are players and as such they are the focus of the game, and they must feel involved, make their own decisions, feel their progress, take on new challenges, participate in a social environment, be recognized for their accomplishments and receive immediate feedback. In short, they should have fun while the goals of the gamified process are achieved. If, beyond the classic sense of fun as entertainment, we assume that fun 
is the reward of the brain to learn new things [8], the link between learning and fun is the key to our proposal of gamification of the learning process.

Gamification is not just a question of adding game-like elements (attractive interfaces, medals, progress bars, leader boards...) to the process, leaving its essence unchanged. On the contrary, it must affect the whole process and it often involves reengineering it, so that the key aspects of gamification are incorporated: fun, motivation, autonomy, progressiveness, immediate feedback and error handling. The aim of this article is to determine from our experience the keys of gamification, as they are reflected in our proposal PLMan [9], explained in detail in section IV.

In the following section, the potential of video games is discussed and some works about gamification applied to education are reviewed. In the third section our proposal is contextualized, specifying the field of application and describing the incremental innovations that have been implemented over time. In section four, the gamified learning system PLMan is described, in its present form, as a result of the incorporation of the accumulated experience designing educational video games. Finally, in the fifth section the lessons learned are summarized, for our reflections to be useful to teachers interested in incorporating gamification to their subjects. The paper finishes with some conclusions and references that allow the readers to delve into these issues.

\section{GAMIFYING THE LEARNING PROCESS}

In the previous section some different definitions of gamification have been reviewed, stating that gamification uses elements from the world of video games. That is why, before studying the gamification concept, a quick review about video games and their use in education is needed. Video games have changed the way young people (and adults) conceive reality and interact with each other [10, 11]. One can say that good video games have the ability to optimally convey much information of a particular type, causing the player to pursue more information. According to Prensky [12, 13] video games attract players for several reasons: they encourage participation, motivate users to gradually achieving small goals, offer rewards or immediate punishments, and allow the difficulties of each level to be adjusted according to the player's skills. Hamari et al. [14] have investigated the impact of flow, engagement and immersion in game-based learning environments. Although most psychological studies focus on the negative effects of video games on adolescents, there are other studies that argue and document the benefits: voluntariness, competitiveness and cooperation, immersion, sense of control, achievement of goals (objectives), but especially satisfaction. Granic et al. [15] have conducted an extensive review of the literature on the benefits of video games and their potential.

Gamification aims to achieve the same objectives in other areas than entertainment, without using video games, but taking advantage of their experience and methods: immediate feedback, autonomy to decide, open situations, infinite retries, progressiveness, clear and simple rules, realtime evaluation, and so on. However, as aforementioned, fun is the key aspect of any gamified proposal. Fun involves new information fixed in the brain, so that the secret of optimal learning lies in the fun [8]. Good games get this fun, while the player learns their contents $[16,17,18]$. Analysing how games achieve the objective of fun is essential to design similar strategies in other areas and get to convey the information we want to be learned and fixed.

It is important to note that the information transmitted by video games is mainly practical instead of theoretical. Video games, as the basis of gamification, teach us what information our brain prefers and what it should be done to produce more and better learning, mainly at the practical level. The principles of video games can help us achieve an innovative and effective training model, that particularly enhances student motivation, and the mechanisms to measure real progress in learning, that is, a truly continuous formative evaluation [19].

There are several studies on the use of gamification in the learning process $[20,21]$, at different educational levels and countries. Da Rocha et al. [22] evaluate the effectiveness of gamification platforms as a strategy for participation of students in the eighth year of primary school in Brazil. De Marcos et al. [23] study and compare several approaches already established (such as educational games and social networks) with other more innovative models (gamification) in terms of learning performance in an undergraduate course. In Mora et al. [24] a complete review of design frames for gamification can be found. The interesting experience of Gonzalez et al. [25] must be highlighted; they present a conceptual architecture of an intelligent tutoring system that includes elements of gamification as key components. Another example is the work of Dominguez et al. [26], who describe a gamification plug-in for an elearning platform, which also allows the collection of quantitative and qualitative data during the process. BorrasGene et al. [27] use gamification to improve motivation in a Massive Online Open Course (MOOC). To end this review, Contreras-Espinosa and Eguia [28] include in their book different experiences that are being developed today in the Spanish classrooms. These works are just a sample of all academic studies that are being generated around the gamification in education.

According to NMC Horizon Report 2013 [29], the gamification would be one of the two technologies experiencing a growing interest in education in the medium term (two to three years). The report further stated that the use of gamification and video games, in a broad sense, are two sides of the same coin. After three years, the NMC Horizon Report 2016 [30] indicates that the stage of defining and using these concepts is already passed, but new perspectives, such as learning measurement, personalized learning and adaptive learning have appeared. These new proposals support the background vision of gamification concept as a redesign of the learning process. A gamified design of the learning process allows the automatic collection of information. Moreover, the analysis of this information, along with the design of a progressive and autonomous learning, will help the system adapt learning to the students' capabilities.

Therefore, it can be stated that education is one of the 
fields where gamification is called to become a disruptive innovation, particularly in technology-based learning (elearning) and lifelong learning. In the following section, a review of our innovation experiences is done to explain how they led us to the current proposal for gamified learning.

\section{ANTECEDENTS: CLASSIC INNOVATIONS}

Our experience of gamification is taking place in the teaching of Logic in undergraduate degrees in Computer Engineering and Multimedia Engineering, at the University of Alicante in Spain. This proposal is not new, but it is the result of the evolution and the progressive developing of new ideas and the search for more effective teaching.

Since its inception, the degrees of computing at the Polytechnic School of the University of Alicante have incorporated the study of Logic, as a first year compulsory subject, called First-Order Logic (4.5 credits $=3$ theory credits +1.5 practice credits). The syllabus was adapted to the specific needs of university students of computer engineering with a highly computational approach [31] and giving the student a vision of Logic based on the formalization of knowledge and automation of various forms of human reasoning [32]. Given the difficulty of formal and non-computer subjects, and seeking to motivate students, this subject has always been approached from the common elements of Logic and Programming [33]. In the practical part, the logic programming language Prolog has been used, based on the first-order predicate calculus and widely used in Artificial Intelligence research. All these proposals were aimed at contextualizing the matter (what), both in the university environment (where) and in the professional scenario (why).

Another aspect that was taken into account when researching about the teaching of Logic was the use of specific computer tools for support. Once the existing tools were analysed, it was determined which ones to use and what needs were not met. Thus the design and implementation of educational tools to assist our students in the learning of Logic were addressed. An example is ADN (from Spanish Asistente para la Deducción Natural, that is, Natural Deduction Wizard), which is a web application for learning the technique of inference of Natural Deduction, which supervises and verifies that the logic formulas are syntactically correct and the obtained sequence (deduction steps) is correct [34]. The use of Information Technology in the teaching process has been one of the areas where we have focused more. Its unstoppable incorporation into the education space should not serve to preserve the old ways of teaching but to adapt them to the new digital spaces in which the world is developing.

Furthermore, the expressive power of Prolog programming language and the motivating character of the games have been used in the practical part of the subject for solving several logic games [35]. Playing is inherent to human beings [36] and the game is a driving element of mental development [37], it improves learning and arouses curiosity, so the games are a great teaching tool. It is common to find sections of mathematical and logic games in scientific journals. In addition, games need Logic for its resolution. We have always been aware of the enormous educational potential of games, so the step to video games was a natural evolution. The objective with the use of games and video games in education is that our students learn more, learn better and enjoy while learning.

In 2004, within the program of Research Networks on University Teaching of the University of Alicante, the Red ilógica [38] was born. This network is dedicated to research in university teaching of Logic, in the use of information technology in Logic teaching and learning and its presence on the Internet. This network was responsible for organizing complementary activities (conferences, awards, contests...) that will connect the Logic with the interests of students. It also allowed us to approach the world of video games from the perspective of Logic. The interest in the game was already sown at the University of Alicante, and the incorporation to the European Higher Education Area (EHEA) and the revision of all curricula, allowed the Polytechnic School of the University of Alicante propose the Degree in Multimedia Engineering with an itinerary of Creation and Digital Entertainment, mainly dedicated to the design and development of video games. The matter of Logic, where this teaching experience belongs to, is part of the first year subject Mathematics I (6 ECTS credits).

Finally, a particularly remarkable milestone representing the germ of the current proposal for gamified learning is the Logic Programming Contest. In February 2006, in the framework of the Cultural Week of the Polytechnic School, the first Logic Programming Contest was organized, which aimed to motivate students and encourage their interest in the subject of Logic, participating in an event where they should present their knowledge about the Logic Programming Paradigm using Prolog language by developing a video game in phases. Next, in the second edition of the competition, the exercise was the implementation of a Pac-man game in Prolog, which can be considered the seed of PLMan system that will be explained later. This competition has been consolidated and has met its tenth edition this year.

All these innovations can be categorized as classic: adaptation of syllabi, use of games, incorporation of information technologies to the educational process, search for specific IT tools for learning the art and design of new tools, and implementation of recreational activities additional to classes. Despite representing improvements in teaching, these innovations were not completely satisfying. The design of fun activities that allowed and favoured creativity and proactivity produced a greater motivation, and students perceived them as useful so that their participation was increased. However, the subject was still suffering some of the problems that characterize educational innovations: an increment in teachers' workload that delayed the assessment and provoked a slow feedback to students. As a consequence, the system was difficult to scale and had a high maintenance cost.

All these experiences led us to PLMan project, described in detail in the next section, which can be considered as a turning point in our design of the teaching process. Not yet talked about gamification, we did not even know the term, but these seminal works were essential to reach the current situation. 


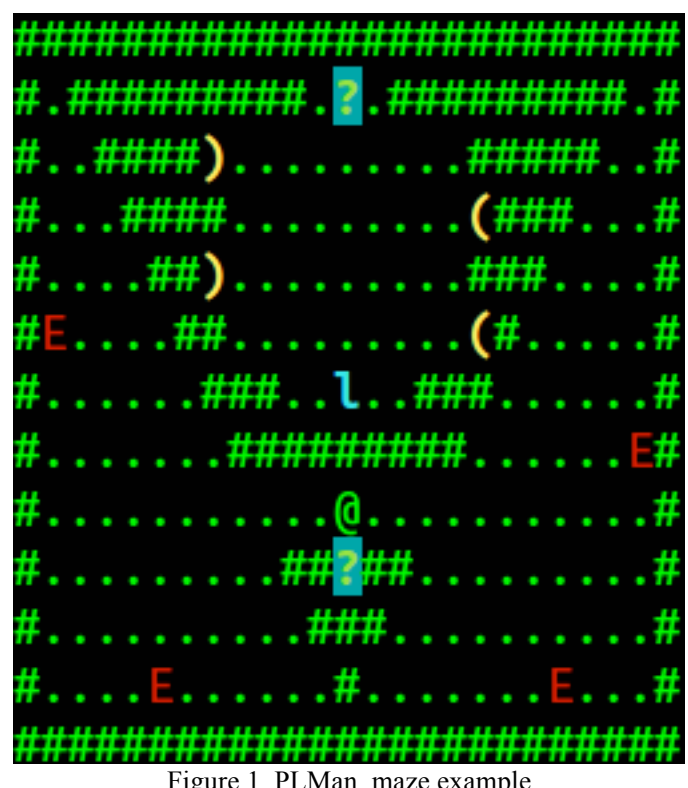

Figure 1. PLMan maze example

\section{PLMAN SYSTEM DESCRIPTION}

In this section, PLMan system [39] is described, as a personalized automated gamified learning system [40, 9]. As aforementioned, this system supports two first year courses of Degrees in Computer Engineering and in Multimedia Engineering. It aims to introduce students in the field of Logic. Students learn the Prolog programming language along the practice classes of the course, programming the artificial intelligence of a Pac-Man like character, using a knowledge base in Prolog. To pass each level of the game, the character must go through different mazes eating the dots and avoiding all enemies.

The game mazes are presented in text mode (Figure 1), so that each symbol has a different meaning. The main character is PLMan, represented by the character "@". The mazes are rectangular and closed, so that the character "\#" represents the maze boundaries, being a solid object or wall that cannot be crossed. The characters "." are the dots, which are disappearing as PLMan passes over them. The "E" and "F" characters are the enemies and ghosts, who are dynamic and may have different behaviours or even attack. If they directly come into contact with PLMan, he dies and the game ends. There are other characters that represent different objects or obstacles.

To overcome a maze, the students must create a program with the actions to be performed by the main character, PLMan, to eat all dots, using the knowledge base that provides the game itself. These actions (doAction) may be a movement (move) in the four cardinal directions (up, down, left, right), or object handling (get, drop, use), making decisions relying in a vision sensor (see) which lets the character see what the eight cells around PLMan contain. Thus, solving a maze is to implement code in the form of rules of movement and handling objects that guide the path of PLMan in the maze.

For the first mazes simple rules such as "If you see an enemy to the right, move left" are used, which in Prolog is translated into rule :- see(normal,right, 'E'), doAction(move(left)) (see figure 2). As the course

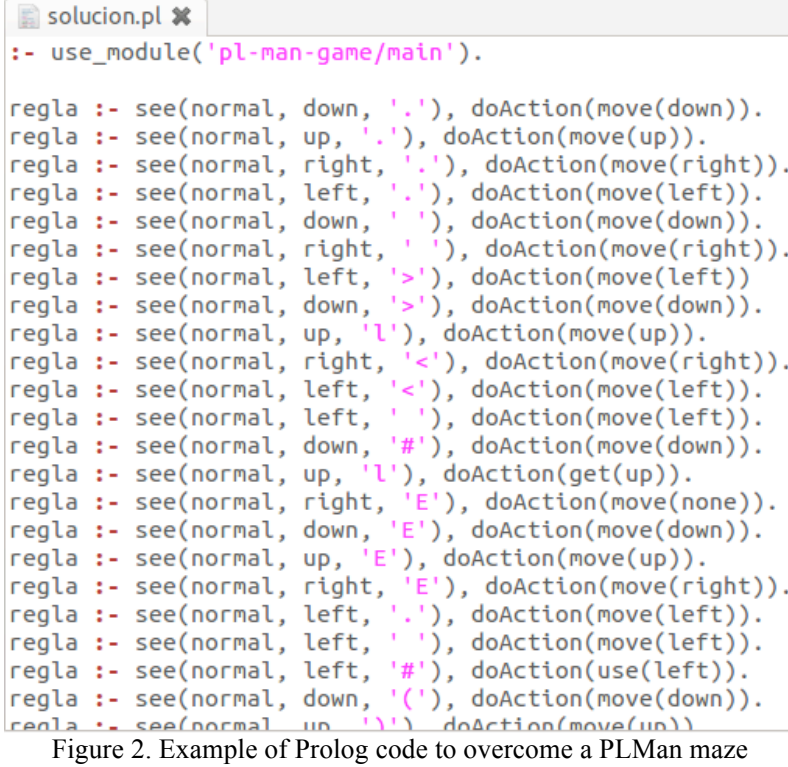

Figure 2. Example of Prolog code to overcome a PLMan maze

progresses, the mazes are increasing their complexity and programming requirements, motivating students to learn more about Prolog and to be more creative when building the artificial intelligence that must overcome the mazes.

Over 400 different PLMan mazes have been created, with different designs, objects to pick up and use, enemies and obstacles to overcome and even problems to solve. These mazes are organized into 4 categories or phases and within each category in 5 difficulty levels. All of them have been included in an automatic and gamified Website, which manages the progress of students with PLMan mazes (Figure 3).

Students have to overcome the 4 phases and the last exam phase to get the highest grade in the system. In each phase, they have to solve 1 to 5 different mazes depending on the phase. First, they must select the preferred level of difficulty (from 1 to 5) and the system assigns a random maze, which is different for each student within the same group of practice class. Then, they use the PLMan software to create and test whether their artificial intelligence can overcome the assigned maze. When they get more than $75 \%$ of dots eaten in this maze, the next maze is unlock and they continue to select difficulty.

Figure 4 graphically represents the PLMan system flow from the viewpoint of the student, allowing clearly see the aspects of student autonomy, immediate feedback and automation. The students choose the difficulty (1) and the system assigns a maze (2). On their local computer and after installing SWI-Prolog and downloading PLMan, the students program the artificial intelligence that will allow the character to solve the maze, being allowed to perform as many tests as desired (3), showing the results thereof and the necessary information to fix the possible conflicting aspects (4). When the student is already satisfied with his or her solution, it is delivered to the PLMan website (5), immediately obtaining its correction and its achieved results (6).

The system is designed with the aim of achieving a formative assessment, considering that students need to learn from their mistakes without being penalized for it. Therefore, there is not a limit of deliveries for a given maze. 


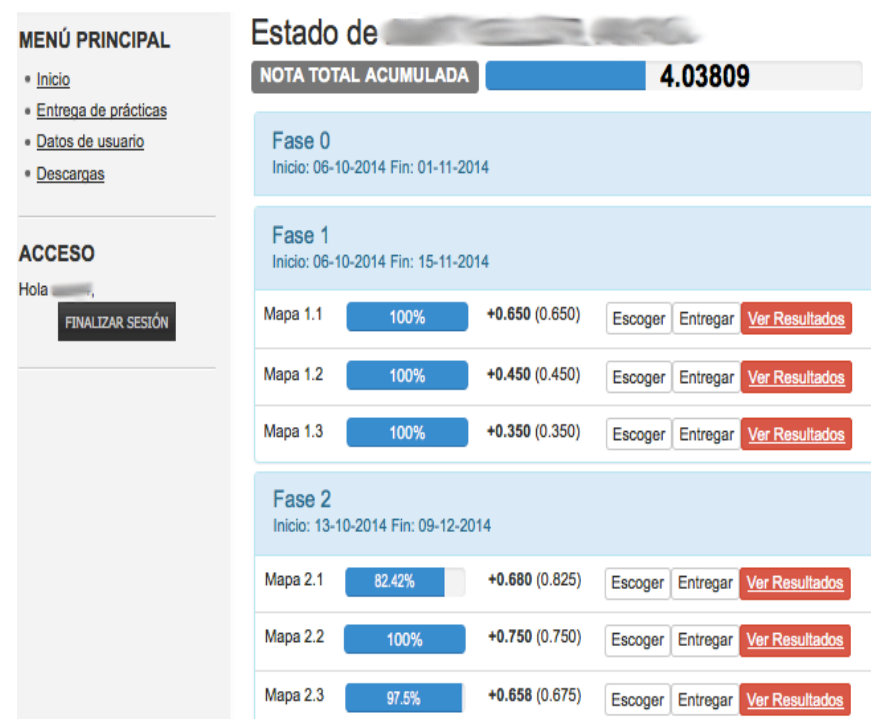

Figure 3. PLMan system website

Students can continue developing and testing their maze solution until they can get over it. They can also follow their own pace by choosing the difficulty levels that make them feel most comfortable, considering that the higher the level of difficulty, the higher the accumulated grade at the end. Students can also stop when they consider it appropriate: for example, if they reach the third stage and have a cumulative grade of 6.5 , they may decide not to continue solving mazes.

In short, we say that PLMan is a gamified system because of:

1) Simplicity: The system starts from some initial affordable and stimulating objectives, progressively increasing its complexity.

2) Feedback: The system provides immediate feedback about the correction of every solution, so that students know instantly if they are doing well.

3) Real time: both interaction and feedback provided by the system occur in real time, so that no time elapses between the delivery of the solution and obtaining the result of the correction.

4) Progress: Students progressively accumulate their grade depending on the chosen difficulty, and the system generates the sense of progress needed to stimulate the challenge and maintain interest.

5) Autonomy: the system provides the possibility of decision making, choosing difficulty levels from simple to complex and performing the exercises at their own learning pace, just adjusting to some deadlines set at the beginning of the course.

6) Individual responsibility: to have the option of imposing a personalized work rhythm, gives the student an individual responsibility for his or her own learning.

7) Treatment of error: the system allows mistakes without penalty, providing the possibility of delivering unlimited solutions to reach an appropriate grade.

8) And, although it is not necessary to be a gamified proposal, it is a game.

With this system the problems of previous innovations have been overcome: teacher overwork, slow corrections, out-dated feedback and evaluative overload, implying a

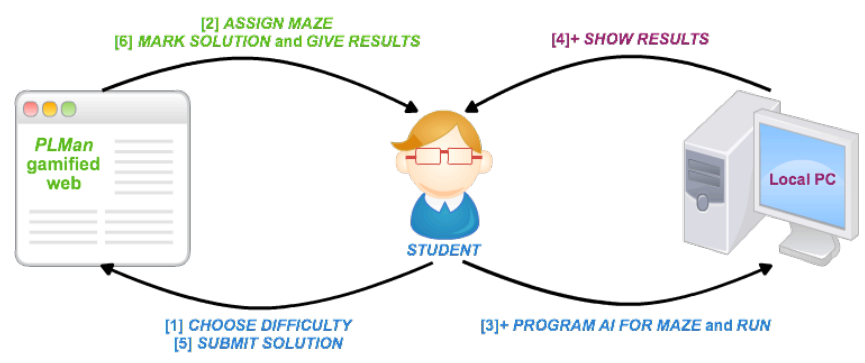

Figure 4. Information flow of PLMan system. The students is in the centre of the process.

difficult scalability and high maintenance costs. Scalability and maintenance have been significantly improved, as the system automatically corrects the mazes. It has increased the students' autonomy and they also get immediate feedback on their work. Furthermore, the professor has been released from time spent on the evaluation, which can be invested in improving and better designing the learning process. Moreover, it has been designed so that learning is progressive, since the difficulty of mazes is incremental. All in all, the most important impact on our students is the fact that this new teaching proposal has managed to motivate and amuse them. To move forward, pending work is the adaptation and measuring of the maze difficulty, closely interrelated aspects. Another desirable aspect would be the automatic or semi-automatic generation of mazes.

\section{LESSONS LEARNED}

This section briefly summarizes the most important lessons learned from our experience, combining the philosophy of game design with our principles about teaching and learning. This is not an exhaustive list, and certainly there are aspects that are not discussed and that could be included. However we believe it is an excellent starting point for those teachers who want to approach the world of gamification.

\section{A. Fun}

One of the best analyses that can be found about what fun is and how we can work with it is in the work of Koster [13]. Fun occurs in situations of pattern recognition by the human brain. This recognition depends on the prior knowledge of the individual and how new information enters and is processed by the brain. All these events trigger the release of dopamine, which is the substance that the brain uses to fix those adaptations that are successful. And precisely this release of dopamine produces positive feelings in the individual, which we call fun.

\section{B. Motivation}

There are two types of motivation: extrinsic (external incentive) and intrinsic (personal satisfaction). The combination of both types can produce a more appropriate level of motivation, so both greatly influence the design of a gamified system. For good results, the elements must be adequately sorted in search of intrinsic motivation, always with a proper balance of extrinsic motivation. Psychological Self-determination theory [41] indicates what factors determine the motivation of people to perform a task, and 
there is a continuum from the demotivation to the intrinsic motivation, with various intermediate degrees of extrinsic motivation. There are three key factors for a person to be in a state of intrinsic motivation to perform a task: autonomy, competence and meaning. The conclusion to be drawn from all this is that we can break down processes into elements (dynamics, mechanics and components) and combine them in such a way that intrinsic motivation is produced (offering autonomy, having meaning and being at the proficiency level of our students).

\section{Autonomy}

We seldom give the students the power to control and decide how their learning process should be or which issues they want to learn. Many teachers think that the syllabus is essential so they constantly become disappointed because they verify that it is absolutely false that students complete the courses mastering the full syllabus. Instead, why don't they let each student choose the parts of the syllabus that really interest him or her and put them into practice autonomously? Few contents are in fact essential: the skills that will enable the students to acquire any knowledge in the future are much more important that the knowledge itself. In contrast, the extra motivation of having autonomy is a propellant of their learning skills that we should not underestimate.

\section{Progressiveness}

There must be an adequate balance between challenge in the proposed activities and capabilities of the students, so that they can enter a state of flow [42], that is, they must have a feeling of complete involvement with the activity, with a high level of enjoyment and fulfilment. In order to advance in the flow channel, it is important to have a structure of levels. To maintain the challenge and sense of progression, there must be achievement levels to overcome and a system of unlocking the next level.

\section{E. Feedback}

Feedback is one of the big keys not just in gamification, but also in any educational process, since the basis of any learning process is communication. Efficient communication requires substantial, appropriate and, whenever possible, immediate feedback.

\section{F. Treatment of error}

The current university education system sets to normal the fact of penalizing the error by subtracting points, and it considers that only the students that get right at a first try are good students. But instead, the errors are one of the greatest sources of progress and learning. Error analysis and its perception as normal make the individuals less fearful and more anxious to experiment and try. However, the punishment of error gets just the opposite: create lock for the fear of being wrong, and trauma in those who are wrong, thinking that mistakes makes them less valid. A video game will not consider the player less skilled if it managed to finish after a hundred attempts. The important thing is to learn until being able, and mistakes are part of learning.

\section{G. Experimentation and creativity}

When exercises or tasks are designed, usually they are made with an approach that only leaves room for a possible solution and result. Not surprisingly, multiple-choice tests are still the kings of the evaluative tests. The reality is not closed and it admits infinite possible interpretations. This characteristic is what allows experimentation and results in creativity. (Good) games also have this feature. Win or lose in a game is often a matter of ingenuity and complex skills. In fact, most of the so-called educational games have failed when eliminating the continuous play spaces, and replace them with test questions to see if the student knows the lesson.

\section{H. "Tinned" gamification}

Web sites with "precooked" gamification systems typically provide some tools for creating scoring systems, leader boards and medals objectives. They also tend to allow the creation of missions or challenges, as a set of objectives or medals to get, in order to complete these challenges. However, as seen above, the mechanics, dynamics and components are not the only elements of fun of video games. Therefore, it is important to deeply analyse the actual usefulness of precooked or tinned gamified products before deciding to use them.

\section{CONCLUSIONS}

Video games are a reality and its penetration rate in the daily lives of our young people is very high. We have seen that video games have features that can be exploited in the learning process. Therefore, not just video games, but also the philosophy that encloses game design are beginning to be applied in the educational world. The gamification of the teaching process can help us in our educational innovations, but above all, it can make them sustainable.

Practicing, trying and experimenting should help us to learn what is the best way to combine the elements to produce motivating and full of content experiences. However, there is a question that is still unanswered. If the elements are not the gamification, and just transplanting them probably will not give satisfactory results; if the SelfDetermination Theory and frameworks do not tell us how the elements should be combined, so where does the gamification reside? What is that magic component that makes the difference between a good gamification and a mere dressing?

The secret ingredient that makes the gamification a truly special experience is fun. Fun is a consequence of brain adaptation to pattern recognition, that is, it is a consequence of learning. The traditional belief is that fun promotes learning, but fun really plays an essential role in learning. The existence of fun during the tasks of the course is an important indication that learning is occurring, and at the same time the cycle is fed back (due to dopamine), so that our students want to continue to perform more tasks.

Many of our feelings are a result of the release of certain substances whose aim is amending cognitive functions and preparing the body systems for certain situations. That means that feelings are an inevitable part of learning and we must take them into account. It is very important to consider how our brain works. Cognitive science tells us that only what draws attention and generates excitement can be truly 
learned. A new discipline is thus emerging, the so-called Neuroeducation [43], that is based on the data provided by scientific research, advocates for change, innovation and improvement of teaching and learning.

\section{REFERENCES}

[1] Ramírez, J.L. (2014). Gamificación. Mecánicas de juegos en tu vida personal y profesional. SC Libro.

[2] Marín, I. y Hierro, E. (2013). Gamificación. El poder del juego en la gestión empresarial y la conexión con los clientes. Empresa Activa.

[3] Gamificación. (2 de marzo de 2016). Gamificación. Recuperado de http://www.gamificacion.com.

[4] Gartner. (2 de marzo de 2016). Gartner IT Glossay. Gamification. Recuperado de http:// www.gartner.com/it-glossary/gamification-2.

[5] Deterding, S.; Dixon, D.; Khaled, R.; y Nacke, L. (2011). "From game design elements to gamefulness: defining gamification". In Proceedings of the 15th International Academic MindTrek Conference: Envisioning Future Media Environments, ACM, pp. 915.

[6] Kapp, K.M. (2012). The Gamification of learning and instruction. Game-based methods and strategies for training and education. Pfeiffer.

[7] Werbach, K. y Hunter, D. (2012). For the Win: How Game Thinking Can Revolutionize Your Business. Wharton Digital Press.

[8] Koster, R. (2004). A Theory of Fun for Game Design. Paraglyph Press.

[9] Villagrá-Arnedo, C., Gallego-Durán, F.J., Molina-Carmona, R. Y Llorens-Largo, F. (2016). "PLMan: Towars a gamified learning system". En Knowledge Society for all. New trends in Education, 3rd International Conference on Learning and Collaboration Technologies.

[10] McGonigal, J. (2011). Reality Is Broken: Why Games Make Us Better and How They Can Change the World. The Penguin Group.

[11] Turkle, S. (2011). Alone Together: Why We Expect More from Technology and Less from Each Other. Basic Books.

[12] Prensky, M. (2001). Digital Game-Based Learning. McGraw-Hill.

[13] Prensky, M. (2006). Don'T Bother Me Mom-I'M Learning! Paragon House Publishers.

[14] Hamari, J.; Shernoff, D.J.; Rowe, E.; Coller, B. Asbell-Clarke, J.; y Edwards, T. (2016). "Challenging games help students learn: An empirical study on engagement, flow and immersion in game-based learning". Computers in Human Behavior, 54, pp. 170-179.

[15] Granic, I., Lobel, A. y Engels, R. C. M. E. (2014). "The benefits of playing video games". American Psychologist, 69 (1), pp. 66-78.

[16] Gallego, F.; Satorre, R. y Llorens, F. (2006). "Computer Games tell, show involve... and teach". En VIII Simposio Internacional de Informática Educativa (SIIE).

[17] Illanas, A.; Gallego, F.; Satorre, R.; y Llorens, F. (2008). "Conceptual Mini-Games for Learning”. En International Technology, Education and Development Conference (INTED).

[18] Gallego, F.J. y Llorens, F. (2011). “QQué nos enseña Pacman? Lecciones aprendidas desarrollando videojuegos educativos". En I Congreso Internacional sobre Aprendizaje, Innovación $y$ Competitividad (CINAIC).

[19] Gallego, F.J.; Villagrá, C.J.; Satorre, R.; Compañ, P.; Molina, R.; Llorens, F. (2014). "Panorámica: serious games, gamification y mucho más". ReVisión (Revista de Investigación en Docencia Universitaria de la Informática). Vol. 7, n² 2, pp. 13-23.

[20] Sánchez i Peris, F. J. (2015). Gamificación. Education in the Knowledge Society, 16(2), pp. 13-15.

[21] Minović, M., García-Peñalvo, F. J., \& Kearney, N. A. (2016). Gamification Ecosystems in Engineering Education. International Journal of Engineering Education (IJEE), 32(1B), pp. 308-309.

[22] da Rocha Seixas, L.; Gomes, A.S.; y de Melo Filho, I.J. (2016). "Effectiveness of gamification in the engagement of students". Computers in Human Behavior, 58, pp. 48-63

[23] de-Marcos, L.; García-López, E.; García-Cabot, A. (2016). "On the effectiveness of game-like and social approaches in learning. comparing educational gaming, gamification \& social networking". Computers \& Education, 95, pp. 99-113.

[24] Mora, A., Riera, D., González, C., y Arnedo-Moreno, J. (2015). “A Literature Review of Gamification Design Frameworks". IEEE explorer

[25] González, C., Mora, A., y Toledo, P. (2014). "Gamification in intelligent tutoring systems". pp. 221-225 ACM Press.

[26] Domínguez, A., Saenz-de Navarrete, J., de Marcos, L., FernándezSanz, L., Pagés, C., y Martínez-Herraíz, J.J. (2013). “Gamifying learning experiences: Practical implications and outcomes". Computers \& Education 63, 380-392.

[27] Borrás-Gené, O., Martínez-Nuñez, M., y Fidalgo-Blanco, Á. (2016) New Challenges for the Motivation and Learning in Engineering Education Using Gamification in MOOC. International Journal of Engineering Education, 32(1B), pp. 501-512.

[28] Contreras-Espinosa, R. S. y Eguia, J.L. (2016). Gamificación en aulas Universitarias. Institut de la Comunicació, Universitat Autònoma de Barcelona.

[29] Johnson, L., Adams, S., Cummins, M., Estrada, V., Freeman, y A., Ludgate, H. (2013). The NMC Horizon Report: 2013 Higher Education edition. New Media Consortium.

[30] Johnson, L., Adams Becker, S., Cummins, M., Estrada, V., Freeman, A., y Hall, C. (2016). NMC Horizon Report: 2016 Higher Education Edition. New Media Consortium, EDUCAUSE Learning Initiative.

[31] Llorens, F. y Castel, M.J. (1996). "Lógica de Primer Orden en las Ingenierías Informáticas”. En II Jornadas Nacionales de Innovación en las Enseñanzas de las Ingenierías.

[32] Llorens, F.; Escolano, F.; Pujol, M. y Colomina, O. (1998). "Formalización del Razonamiento". En IV Jornadas de la Enseñanza Universitaria de la Informática (JENUI).

[33] Llorens, F.; Satorre, R.; Escolano, F. y Arques, P. (1999). "Deducción Natural versus Computación". En V Jornadas de la Enseñanza Universitaria de la Informática (JENUI).

[34] Llorens, F. y Mira, S. (2000). "ADN (Asistente para Deducción Natural) Natural Deduction Assistant". En First International Congress on Tools for Teaching Logic.

[35] Llorens, F.; Castel, M.J.; Mora, F. y Villagrá, C. (2001). Los Juegos como Herramienta Docente. Formalización de Juegos Lógicos en Prolog. En VII Jornadas de la Enseñanza Universitaria de la Informática (JENUI).

[36] Huizinga, J. (1949). Homo ludens. A study of the play-element in culture. Routledge \& Kegan Paul.

[37] Vygotsky L.S. (1978). Mind in Society: The Development of Higher Psychological Processes. Harvard University Press.

[38] Red iLógica. (2 de marzo de 2016). Red ilógica de investigación en la docencia universitaria de la lógica, del uso de las tecnologías informáticas en su enseñanza/aprendizaje y su presencia en internet. Recuperado de http://www.dccia.ua.es/ilogica.

[39] PLMan. (2 de marzo de 2016). Recuperado de https://plman.i3a.ua.es.

[40] Castel, M.J.; Gallego, F.J.; Pomares, C.; Suau, P.; Villagrá, C. y Cortés, S. (2009). "e-Valuación en tiempo real". En XV Jornadas de la Enseñanza Universitaria de la Informática (JENUI).

[41] Ryan, R.M. y Deci, E.L. (2000). "Self- determination theory and the facilitation of in- trinsic motivation, social development, and wellbeing". American Psychologist, 55(1), pp. 68-78.

[42] Csikszentmihalyi, M. (1990). Flow: The psychology of optimal experience. Harper Perennial.

[43] Mora, F. (2013). Neuroeducación. Alianza Editorial.

Faraón Llorens-Largo is Professor of Computer Science and Artificial Intelligence at the University of Alicante. He is Bachelor in Primary School Teacher, Degree in Computer Science and $\mathrm{PhD}$ in Computer Engineering. He has held various management positions, such as as Director of the Polytechnic School (2000-2005) and Vice chancellor for Technology and Educational Innovation (2005-2012) at the University of Alicante, and Executive Secretary of the Sectorial Commission for Information and Communication Technology of the Conference of Rectors of Spanish Universities (CRUE) between 2010 and 2012. He is currently the director of the Santander-UA Chair of Digital Transformation of the University of Alicante. It belongs to the research group "Industrial Computing and Artificial Intelligence" (I3A). His research lines are framed in artificial intelligence and video games, focused on improving the learning process and the IT governance leading to digital transformation, both in organizations and at a personal level.

Francisco J. Gallego-Durán is Assistant Professor at the Department of Computer Science and Artificial Intelligence at the University of Alicante. $\mathrm{He}$ is Degree in Computer Engineering and $\mathrm{PhD}$ in Computer Engineering, with International Doctor Mention. Member of the Spanish Association for Artificial Intelligence (AEPIA), the Association of University Computing Teachers (AENUI), and the Spanish Society for Science of Videogames (SECiVi). He belongs to the research group "Industrial Computing and Artificial Intelligence" (I3A). His main interests and research include Machine Learning, Neuroevolution, Genetic Algorithms, Neural Networks, Softcomputing, Gamification, Video games and innovative teaching methods. He has participated as technical coordinator and developer of video games on numerous projects, learning and gamification. He has experience in the application of information technologies to the educational process, in the design and development of video games and the transfer of 
these principles and techniques to other fields (gamification), and the use of artificial intelligence techniques in data mining and predictive systems.

Carlos J. Villagrá-Arnedo is Professor of Computer Science and Artificial Intelligence at the University of Alicante. He participated in the commission rapporteur of the Degree in Multimedia Engineering and he has been its Academic Head (2010-2013). Currently, he is a member of the commission of that grade, and coordinator of the itinerary of Creation and Digital Entertainment in the fourth year. He participates in teaching innovation projects related to the EHEA belonging to the REDES program of the University of Alicante. He is also member of AENUI (Association of University Computing Teachers). It belongs to the research group "Industrial Computing and Artificial Intelligence" (I3A). His research is framed in the field of artificial intelligence and game development.

Patricia Compañ-Rosique is Professor at the Department of Computer Science and Artificial Intelligence at the University of Alicante. She has held various management positions, such as Communications Coordinator at the Polytechnic School (2008-2009), Deputy Director of Computer Engineering of the Polytechnic School (2009-2012) and Deputy Coordinator of the Polytechnic School (2012-2013). Her teaching focuses on programming, artificial intelligence and virtual reality. She belongs to the research group "Industrial Computing and Artificial Intelligence" (I3A). The research lines in which she works fall within the field of application of AI techniques, specifically evolutionary algorithms for solving mathematical problems. Also in game development and application of digital technologies to education. She participates in many educational innovation projects related to the EHEA belonging to the REDES program of the University of Alicante. She also belongs to AENUI (Association of University Computing Teachers).

Rosana Satorre-Cuerda is Professor at the Department of Computer Science and Artificial Intelligence at the University of Alicante. She has held various management positions, such as assistant director of the Department of Computer Science and Artificial Intelligence (2000-2004), acting director of the Department of Computer Science and Artificial Intelligence (2004-2005), Deputy Director of Engineering degrees and Computer Engineering of the Polytechnic School (2005-2009) and Secretary of the Polytechnic School (2009-2013). She participates in teaching innovation projects related to the EHEA belonging to the REDES program of the University of Alicante. She belongs to the research group "Industrial Computing and Artificial Intelligence" (I3A). She also belongs to AEPIA (Spanish Association for Artificial Intelligence) and AENUI (Association of University Computing Teachers).

Rafael Molina-Carmona is Professor at the Department of Computer Science and Artificial Intelligence at the University of Alicante. He is Degree in Computer Science at the Polytechnic University of Valencia and $\mathrm{PhD}$ in Computer Engineering at the University of Alicante. He belongs to the research group "Industrial Computer and Artificial Intelligence" (I3A). His research is mainly distributed in two fields: artificial intelligence applied to the design and manufacturing computer-assisted computer graphics; and video game-based learning and gamification. He has more than 50 scientific publications, 16 of them in high impact journals and other national and international conferences. He has been principal investigator in 4 projects public calls or companies, and researcher participating in some 12 competitive projects. 